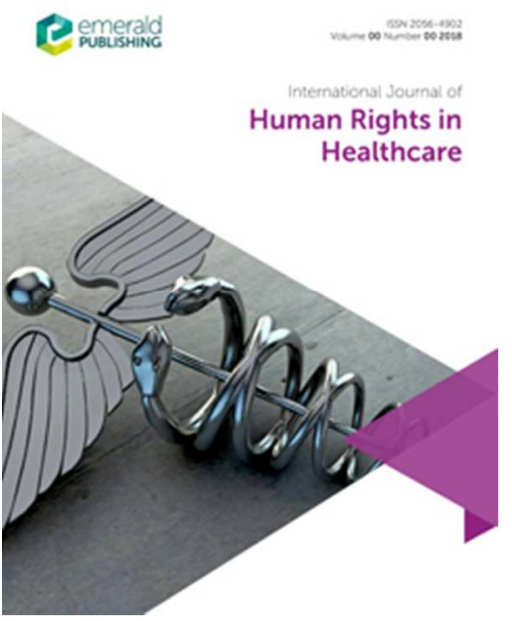

\title{
Reducing Hypovitaminosis D among Somali immigrants in Minnesota: A narrative review
}

\begin{tabular}{|r|l|}
\hline Journal: & International Journal of Human Rights in Healthcare \\
\hline Manuscript ID & IJHRH-04-2018-0033.R1 \\
\hline Manuscript Type: & Review Paper \\
\hline Keywords: & Somali Immigrant, Vitamin D, Minnesota, Cultural competency \\
\hline \multicolumn{2}{|c}{} \\
\hline
\end{tabular}

\section{SCHOLARONE}




\begin{abstract}
Somalia is an East African nation with a history of civil unrest that produced a significant influx of refugees in the United States in the last 25 years. Between 2000 and 2010, 40\% of all U.S. Somali refugees settled in Minnesota, which produces new cultural and health challenges for local communities and the state government. One such challenge is vitamin D deficiency, or hypovitaminosis D (Hv-D). Hv-D is developed through insufficient exposure to sunlight and low nutrient intake leading to increased risk for weakness and inflammation, oral health problems, diabetes, cardiovascular and autoimmune diseases, and malignancies. In this narrative review, demographic, geographic, and cultural information about Somali immigration is discussed. Recent data suggests Somalis living in northern climates (Minnesota, US, Helsinki, Finland, Sweden, the United Kingdom) experience significant deficiencies in vitamin D. Vitamin D is stimulated by ultraviolet light exposure, a balanced and healthy diet, and dietary supplementation. High unemployment rates affecting access to health information and clinical services, significant cultural differences, and climate differences predispose this population to Hv-D. Health education and health promotion programming at the community and state level in Minnesota should recognize the risk factors associated with Hv-D and the vulnerability of Somali refugees. Current and future health programming should be re-assessed for adequate attention to vitamin D deficiency and cultural competency associated with the Somali immigrant population.
\end{abstract}

\title{
Keywords
}

Somali Immigrant; Vitamin D; Minnesota; Cultural competency 


\section{Introduction}

The Somali population in the United States is steadily increasing and the state of Minnesota is a growing place of settlement (Njeru et al., 2016). There are several noted distinctions between living conditions in Somalia and Minnesota with key differences being climate, culture, and diet. Some aspects of these differences place Somali people at increased risk for development of vitamin D deficiency in the transition from Somalia to Minnesota. Vitamin D deficiency, or hypovitaminosis D (Hv-D), is a condition associated with negative health outcomes in children and adults including muscle weakness, rickets, joint inflammation, dental caries and tooth loss, and increased risk for diabetes, cardiovascular and autoimmune diseases, and malignancies (Podd, 2015). Furthermore, Somali people may not identify the public health-related risks of the differential geographic and climatic aspects between Somalia and Minnesota and therefore not recognize the need to alter lifestyle choices to prevent vitamin D deficiency.

Research on this particular topic is lacking. The prevalence of Hv-D among recent Somali immigrants living Minnesota remains ambivalent. In this narrative review, demographic and geographical information about Somali immigration is discussed. This leads to the examination of risk factors for vitamin D deficiency among Somali immigrants in Minnesota and the potential negative health consequences of vitamin D deficiency. Exposure of these risk factors suggests the need for further research on this topic, particularly research to identify prevalence data. Finally, recommendations for lifestyle adjustments for Somali immigrants, barriers to these adjustments, and recommendations for changes within the Minnesota health care system are offered for Hv-D prevention. 


\section{Somali Immigration to Minnesota}

Somalia is an East African nation with a history of civil unrest. A civil war began in Somalia in the early 1990s, which prompted many Somali refugees and immigrants to move to the US (Njeru et al., 2016), a trend that has continued over the past 25 years. Between 2000 and 2010, the population of Somali people living in the US has doubled (Njeru et al., 2016). Somali people have moved to a variety of places in the US; however, Minnesota has the largest Somali population (Arcan et al., 2014). Between 2000 and 2010, 40\% of all U.S. Somali refugees and immigrants settled in Minnesota (Njeru et al., 2016).

Based on data from the Minnesota Department of Health (MDH), 1,425 Somali people immigrated to Minnesota in 2016, 1,006 immigrated in 2015, 1,128 immigrated in 2014, 843 and 809 individuals immigrated in 2013 and 2012, respectively (Minnesota Department of Health, 2017). The largest number of recent Somali immigrants reside in Hennepin county, which welcomed 404 new Somali immigrants in 2015 alone (Minnesota Department of Health, 2017). Hennepin County is the largest county in the state and is home to the city of Minneapolis (Minnesota State Demographics Center - Department of Administration, 2017).

\section{Challenges Related to Health Care Among Recent Somali Immigrants}

Attitudes of Somalis towards preventive medicine should be addressed when considering the topic of Hv-D prevention. According to the Centers for Disease Control and Prevention, the concept of preventive medicine is foreign to many Somalis (Centers for Disease Control and Prevention, 2008). Therefore, adherence to prophylactic treatment measures may be low. A study comparing recent Somali immigrant patients and non-Somali patients in Minnesota suggested that adherence to recommended preventive treatments such as colorectal cancer screening, mammography, and influenza vaccines is lower among recent Somali immigrants (Morrison et 
al., 2012). Moreover, Somali patients living in Minnesota and Western medicine practitioners may have differing perspectives on disease prevention and associated expectations of healthcare providers (Pavlish et al., 2010). While Western medicine practitioners generally view health problems as biologically mediated, Somali culture views the root of some health issues as spiritual dissonance, social disconnection, and sadness (Pavlish et al., 2010) and some Somali women express more faith in God than medical science (Hill et al., 2012). In fact, reading and following the Holy Quran is seen by some Somali refugees as a viable treatment option for both mental and spiritual ailments (Clarkson Freeman et al., 2013). Likewise, God's will is seen as a major determining factor when considering if an individual will recover from illness (Clarkson Freeman et al., 2013). Moreover, Western healthcare practitioners often focus on efficiency and expediency rather than building rapport and understanding, while Somali women expect to build relationships with their healthcare provider (Pavlish et al., 2010).

\section{Clinical Implications of Vitamin D deficiency}

Vitamin D deficiency is a potentially serious chronic condition that is not well understood or easily recognized. In children, vitamin D deficiency can lead to rickets, a disease that leads to malformation of weight-bearing bones (Mahan et al., 2012), which can impair the child's ability to walk. In adults, vitamin D deficiency can increase the risk of common cancers, autoimmune diseases, hypertension, infectious diseases, osteomalacia, and osteoporosis (Mahan et al., 2012, Islam et al., 2012). Recent clinical data also suggests vitamin D deficiency is associated with adverse cardiovascular events and increased overall mortality (MatyjaszekMatuszek et al., 2015). In a recent study on Somali immigrants in Sweden who were either pregnant or new mothers, an association between Hv-D and decreased muscle strength was 
found (Kalliokoski et al., 2013). Muscle strength was measured via hand grip strength and ability to complete several upper leg exercises such as squatting, standing on one leg, standing from a chair and lifting of the hips. Decrease in muscle strength may be dangerous for the pregnant population due to the strength required during labor and during the care of a child.

A large cross-sectional study $(n=14,213)$ was conducted using data from the National Health and Nutrition Examination Survey (NHANES) III (Frei et al., 2015). Allostatic load, described as "a multi-systemic measure of physiologic dysregulation known to be associated with chronic exposure to stress and adverse health outcomes" (Frei et al., 2015, p. 1), and its relationship to vitamin D status was analyzed. Allostatic load components included blood pressure, total cholesterol, waist-to-hip ratio, total cholesterol, and cortisol levels. A statistically significant inverse relationship between vitamin D levels and allostatic load was found (Frei et al., 2015). This may be related to the large role vitamin D plays in immune function and consequently its ability to reduce bodily inflammation (Frei et al., 2015).

The clinical implications of Hy-D stress the importance of risk factor examination. Living at high or low latitudes is a risk factor for Hy-D (Rhodes et al., 2010). Cutaneous vitamin D synthesis varies greatly by latitude, with individuals living at higher latitudes requiring more time outdoors to promote the same cutaneous vitamin D synthesis as an individual living closer to the equator (Rhodes et al., 2010). The effect of latitude on vitamin D attainability among the Somali immigrant population is evident in studies conducted in Sweden. Somali immigrant women living in Sweden have been found to have lower serum vitamin D levels than native Swedish women (Kalliokoski et al., 2013, Saaf et al., 2011, Demeke et al., 2015). The impact of latitude and season on cutaneous vitamin D synthesis will be discussed in more detail below. 


\section{The Impact of Latitude and Season on Cutaneous Vitamin D Synthesis}

Somalia is located on the Equator (Hadden, 2007). Minneapolis, Minnesota, on the other hand, is located at much higher latitude at approximately $44^{\circ} \mathrm{N}$ (Minnesota Department of Natural Resources, 2017). Somalia's proximity to the equator keeps temperature fairly stable and results in heavy sun exposure (Hadden, 2007). The average temperatures in Mogadishu, Somalia's capital, range from the low 80s $\left({ }^{\circ} \mathrm{F}\right)$ in July to the low 90 s $\left({ }^{\circ} \mathrm{F}\right)$ in April (Hadden, 2007). In southern Minnesota, where the largest number of recent Somali immigrants reside, average high temperatures in July are in the mid-80s $\left({ }^{\circ} \mathrm{F}\right)$ while average highs are in the mid-20s $\left({ }^{\circ} \mathrm{F}\right)$ in January (Minnesota Department of Natural Resources, 2017) and winter temperatures can fall below $0^{\circ} \mathrm{F}$ in this part of the state (Minnesota Department of Natural Resources, 2017). Unfamiliar cold temperatures in the winter months may make recent Somali immigrants less eager to go outside during this time and may negatively impact sun exposure. Although cold temperatures in the winter months may cause anyone living in Minnesota reluctant to spend time outdoors, compounding risk factors for Hv-D may exist among recent Somali immigrants and is discussed below. Another significant climate difference is the presence of snow in Minnesota that covers significant parts of Minnesota for at least 90 days of the year (Minnesota Department of Natural Resources, 2017). Many native Somalis have never seen snow prior to their immigration to Minnesota. This factor may also decrease time outdoors for recent Somali immigrants. These significant climate differences between Somalia and Minnesota have the potential to negatively influence vitamin D status.

Season and latitude both impact vitamin D attainability from sunlight. For example, in San Diego $\left(32^{\circ} \mathrm{N}\right)$, on June $21^{\text {st }}$ at midday, sufficient cutaneous vitamin D synthesis can be 
attained by an individual with white skin from 9 minutes outdoors at midday with $35 \%$ of total body surface area exposed to sunlight (Rhodes et al., 2010). In the same location under the same conditions on December $21^{\text {st }}$, it would take 49 minutes to achieve similar cutaneous vitamin D synthesis. In comparison, at $49^{\circ} \mathrm{N}$ on June $21^{\text {st }}$, time needed to achieve sufficient cutaneous vitamin D synthesis increases from 9 minutes to 11 minutes (Rhodes et al., 2010). In the winter months at $49^{\circ} \mathrm{N}$, time needed increases from 49 minutes to over an hour. Additionally, it may be difficult for an individual to leave $35 \%$ of total body surface area exposed to sunlight on December $21^{\text {st }}$ at $49{ }^{\circ} \mathrm{N}$ due to cold temperatures. Even at $42^{\circ} \mathrm{N}$, cutaneous vitamin $\mathrm{D}$ synthesis may be negligible from November through April (Holick, 1988).

\section{Clinical Effects of Climate Differences}

Studies in other locations with substantial populations of Somali immigrants have investigated the vitamin D status of the native population compared to that of Somali immigrants. Sweden is one such location where several studies have taken place. Sweden is at a slightly higher latitude than Minnesota, at $60^{\circ} \mathrm{N}$ (Kalliokoski et al., 2013); however, the difference in latitude between Somalia and Minnesota and Somalia and Sweden is comparable in the context of effect on vitamin D attainability. In the Swedish study, Somali immigrant vitamin D levels were compared between native Swedish women and Somalis over 18 years of age who were either pregnant or new mothers (Kalliokoski et al., 2013). According to many experts, a vitamin D level of $<20$ nanogram (ng)/milliliter $(\mathrm{mL})$ indicates deficiency, a level of $20-30 \mathrm{ng} / \mathrm{mL}$ indicates insufficiency, and $>30 \mathrm{ng} / \mathrm{mL}$ is considered optimal (Holick, 2009). Approximately one third of the Somali women had vitamin D levels $<4 \mathrm{ng} / \mathrm{mL}$ and $90 \%$ were deficient in vitamin $\mathrm{D}$ 
with a level $<6.25 \mathrm{ng} / \mathrm{mL}$.(Kalliokoski et al., 2013) Almost half of the Swedish women had levels $>20 \mathrm{ng} / \mathrm{mL}$ and only $10 \%$ had levels $<6.25 \mathrm{ng} / \mathrm{mL}$ (Kalliokoski et al., 2013).

The results of this study are corroborated by a similar study in Sweden at $59^{\circ} \mathrm{N}$ conducted after the summer season when serum vitamin D levels are expected to be highest (Saaf et al., 2011). Serum vitamin D levels were compared among pregnant Somali immigrants and Swedish women who were between 7 and 26 weeks gestation. Serum vitamin D levels were significantly different among these populations. Thirty percent of women of ethnic Swedish origin had a level of $>30 \mathrm{ng} / \mathrm{mL}, 55 \%$ had a level between $20-30 \mathrm{ng} / \mathrm{mL}$ and $15 \%$ had a level between $10-20 \mathrm{ng} / \mathrm{mL}$. Twenty five percent of Somali women had a serum vitamin D level of $>5-<10$ and $75 \%$ had a level $</=5 \mathrm{ng} / \mathrm{mL}$ while no women of ethnic Swedish origin were found to have serum vitamin D levels less than $5 \mathrm{ng} / \mathrm{ml}$ (Saaf et al., 2011). Not only is the health of the mother negatively affected by Hv-D during pregnancy, but the health of the developing fetus is as well. The children born to mothers in the aforementioned study underwent a follow-up evaluation at age 4 (Fernell et al., 2015). Particular attention was paid to neurodevelopment due to the high incidence of autism among Somali children living in Stockholm county $\left(59^{\circ} \mathrm{N}\right)$ (Fernell et al., 2015). Only $69 \%$ of the Somali immigrants in the Stockholm study with collectively suboptimal vitamin D levels had optimal pregnancy outcomes compared to $89 \%$ of mothers in Stockholm County as a whole. In this case, pregnancy outcomes is a comprehensive term including miscarriage rate, prematurity, prenatal malformation, Apgar scores, and neurodevelopmental scores at age 4 (Fernell et al., 2015). Children are affected by Hv-D in other northern areas of the world as well. Children residing in the United Kingdom age 0-16 with serum vitamin D levels of $<19 \mathrm{ng} / \mathrm{mL}$ were recognized in primary or secondary care settings over a 4 year period (Modgil et al., 2010). Of these 127 children, 82\% were Somali (Modgil et al., 2010). 
A study conducted at similar latitude $\left(57^{\circ} \mathrm{N}\right)$ assessed bone mineral density (BMD) among Somali women living in Gothenburg, Sweden (Demeke et al., 2015). Somali individuals were originally from $0-10^{\circ} \mathrm{N}$ and had been residing in Gothenburg for at least 2 years. BMD was assessed via dual X-ray absorptiometry (DXA) scan of the lumbar spine and both hips. Serum vitamin D levels were also measured among Somali study participants. Severe deficiency was found in $73 \%$ of Somali individuals $(<10 \mathrm{ng} / \mathrm{mL})$ and only $6 \%$ of Somali participants had a vitamin D level of $>20 \mathrm{ng} / \mathrm{mL}$. In this study a correlation was found between sub-optimal vitamin D levels and low BMD measurements. The BMD of Somali individuals was compared to the BMD of reference population including both white and African-American individuals living in the United States; this normative data was provided by the DXA manufacturer. The BMD of Somali individuals was significantly lower than reference populations which places them at greater risk for osteomalacia, osteoporosis, and bone fractures (Demeke et al., 2015). In addition to Sweden, Minnesota, and the UK, Helsinki, Finland $\left(60^{\circ} \mathrm{N}\right)$ is home to Somali immigrants as well (Islam et al., 2012). An estimated 7,018 Somali immigrants resided in Finland in 2016 (Statistics Finland, 2017). In a recent study, 90\% of the Somali immigrants living in Helsinki were found to have an insufficient vitamin D status (defined as $<20 \mathrm{ng} / \mathrm{mL}$ ) (Islam et al., 2012). Although Minnesota is at a slightly more Southern latitude than Sweden, the effect of sunlight on vitamin D attainability is comparable. Moreover, vitamin D deficiency among Somali individuals living at these latitudes may need to be treated at a dose deemed aggressive by some health care providers. Supplementation of 16,000 IU/day with cholecalciferol for 12 weeks effectively raised depleted serum vitamin D levels to a healthy level among Somali individuals who had been living at $57^{\circ} \mathrm{N}$ for at least 2 years (Osmancevic et al., 
2016). Comparatively, about $1,600 \mathrm{IU} /$ day might be a typical dose for individuals routinely receiving treatment for a serum vitamin $\mathrm{D}$ level less than $30 \mathrm{ng} / \mathrm{mL}$ (Binkley et al., 2011).

\section{Sources of Vitamin D}

Vitamin D can be obtained through three avenues: Synthesis in the skin through ultraviolet light exposure, standard dietary intake, and dietary supplementation. Moderate ultraviolet light exposure is likely adequate for most people to achieve adequate serum vitamin D levels (Mahan et al., 2012). However, melanin in the skin decreases ultraviolet penetration and dark skin has a much higher melanin content than white skin (Mahan et al., 2012). Therefore, populations who have dark skin, such as the Somali population, are at increased risk for inadequate vitamin D synthesis from sun exposure. Living in Northern latitudes and wearing clothing that completely covers the body are also risk factors for inadequate ultraviolet light exposure and therefore inadequate bodily vitamin D synthesis (Mahan et al., 2012). Populations with these risk criteria require increased dietary intake of vitamin D or vitamin D supplementation to prevent deficiency (Mahan et al., 2012). Foods high in vitamin D include fortified dairy products such as milk, yogurt, butter, and cheese, fish such as salmon, mackerel, tuna, and sardines, eggs, fortified cereals and orange juice, cod liver oil, and beef liver (Mahan et al., 2012). Most of these foods are not included in the traditional Somali diet (Centers for Disease Control and Prevention, 2008).

\section{Somali Culture and Demographic Information}

In 1972, Somali became the official language in Somalia and was therefore the predominant language used in the government and school system (Centers for Disease Control 
and Prevention, 2008). Those who were school-aged after 1972 have likely had limited exposure to English (Centers for Disease Control and Prevention, 2008). Therefore, English proficiency may be limited among recent Somali immigrants in Minnesota. Among all forms of communication, Somalis appreciate verbal the most yet Somalia had a literacy rate of $24 \%$ in 2000 (Centers for Disease Control and Prevention, 2008). This should be taken into consideration when providing health education to this population; written materials, even when translated into Somali, may not be effective due to limited literacy.

The Somali diet varies based on region, but overall diversity in the diet is lacking. Many Somali diets consist mostly of ghee, or clarified butter, milk, and meat that has been slaughtered according to appropriate Islamic practices. Cultural themes are strong among this population; $85 \%$ of people residing in Somalia are Somali and share a language, religion, and culture (Centers for Disease Control and Prevention, 2008). As food is a significant part of culture, Somalis may be hesitant to stray from their customary dietary practices.

Somali youth have adopted dietary behaviors in Minnesota that may lead to a diet insufficient in vitamin D. A recent study of ethnic minority groups in Minneapolis/St. Paul, Minnesota emphasized dietary risk factors in Somali youth living in Minnesota using the EAT 2010 survey (Eating and Activity in Teens) (Arcan et al., 2014). Adolescents in 6-12 ${ }^{\text {th }}$ grade were given a 235-item self-report survey and a cross-sectional analysis of the data was completed. All groups studied had low intakes of fruit, vegetables, and milk and high intakes of sugar-sweetened beverages and fast food. Specifically, Somali girls had lower milk consumption than white girls and fast food consumption is high among all Somali youth (Arcan et al., 2014). Low consumption of milk and high consumption of fast food are both contributing factors to poor vitamin D status if fast food replaces more nutrient-dense food options. 
A study of Somali girls age 11-14 living in Minnesota identified cultural and family traditions that emerged as some of the most influential dietary factors influencing vitamin D and calcium consumption (Benbenek and Garwick, 2012). Specifically, girls reported frequent consumption of Somali low vitamin D food staples. Moreover, when asked about high vitamin D and calcium foods, girls reported, "our moms don't know how to cook that food" (Benbenek and Garwick, 2012). Environment, developmental stage, and acculturation were identified as additional influential factors on vitamin D and calcium intake (Benbenek and Garwick, 2012). Strong adherence to consumption of Somali food staples was highlighted in a study on Somali children with type I diabetes living in Minneapolis and St. Paul, Minnesota (Sunni et al., 2015). Carbohydrate counting while consuming Somali food staples was identified as a barrier to achieving euglycemia (Sunni et al., 2015). These studies stress the need for culturally relevant dietary education materials.

When providing healthcare to Somali individuals in the United States, effective communication is key. Adherence to preventive healthcare is better among Somali immigrants residing in Minnesota when interpreter services are utilized (Morrison et al., 2012). According to Steinman et al. (2010), Somali patients have reported "listening, explaining, empathy, addressing specific concerns, repeating important information, offering preventive advice, and sufficient visit time" (Steinman et al., 2010, p. 67) as traits they would like to see in a healthcare provider. Healthcare interventions are more effective when trust is built between the healthcare provider and the Somali patient (Johnson et al., 2009). Therefore, it is concerning that healthcare providers in Finland working with the Somali immigrant population report communication as a barrier to effective healthcare (Degni et al., 2012). Since building rapport through good communication leads to better adherence to healthcare interventions, adequate interpreter 
services are vital when providing education to patients (Carroll et al., 2007). Also, due to the importance of community in the Somali culture, community based participatory research may produce and facilitate the integration of prophylactic services for this population (Johnson et al., 2009).

\section{Culturally Congruent Health Care in Minnesota}

When considering access to health services in the US, it should be noted that $42 \%$ of Somalis in the were unemployed in 2000 (Centers for Disease Control and Prevention, 2008). Unemployment may negatively affect access to health care through limited access to health insurance. Those who are employed may have difficulty with health service copayments. According to year 2000 data from the U.S. Census Bureau, the median annual income for a Somali family in the United States was about $\$ 19,000$ while the median income for a family in the general U.S. population was about $\$ 50,000$ (Centers for Disease Control and Prevention, 2008).

In Minnesota, a health screen is attempted on every Somali immigrant (Minnesota Department of Health, 2014), however, based on 2013 data from the MDH, health screens were performed on 70-95\% of all new Somali immigrants (Minnesota Department of Health, 2014). Health screen parameters include adherence to all recommended MDH immunizations and screenings and subsequent treatment for TB, Hepatitis B, intestinal parasites, lead poisoning, and HIV, as needed (Minnesota Department of Health, 2014). This period of health screening represents an ideal time to introduce Somali immigrants to appropriate preventive health services. In the context of prophylactic vitamin D therapy, a registered dietitian or health educator would be especially helpful. Providing Somali immigrants with culturally sensitive information about 
these health resource providers and then stressing the importance of routine visits may reduce risk of vitamin D deficiency and associated health concerns in the Minnesota Somali population.

Based on the abovementioned data, a health provider visit may be out of reach financially for recent Somali immigrants. Providing a visit free of charge as part of the initial screening process may reduce risk of negative health outcomes associated with Hv-D. A study of Somali immigrants in Bristol, England echoed these potential barriers to care (Ingram, 2009). When assessing the healthcare needs of these individuals, Ingram (2009) found "access to health promotion information, communication needs, and service provision” (Ingram, 2009, p. 26) were identified as areas of great need. As evidenced by the abovementioned clinical implications of Hv-D, these practices may decrease the overall health care costs associated with this problem and improve quality of life for the Somali population in Minnesota. A culturally competent registered dietitian, health educator, or similarly appropriate health care provider should conduct this consultation (Centers for Disease Control and Prevention, 2008). After language proficiency is established, literacy in the native language should be well established as many Somali people primarily use verbal communication (Centers for Disease Control and Prevention, 2008). When literacy is established, the mode of education can be decided upon (i.e. verbal, written, or both) and the health provider could educate the individual on the risk factors for Hv-D that are associated with the move to Minnesota. Negative health outcomes of Hv-D should be discussed and preventive strategies outlined. When discussing preventive strategies, the health educator should note the lack of preventive health care in the Somali culture and broach this subject from an ecological perspective accounting for family and community needs (National Cancer Institute et al., 2012). The healthcare provider should also have respect for the importance of adequate communication and building rapport in this population. 
Due to potential communication and cultural barriers to nutrition education, providing adequate visit length and routine follow up are important considerations. The cultural significance of food should also be respected. Potential preventive strategies include the inclusion of high-vitamin D foods in the diet, spending time outdoors throughout the year, and possibly vitamin D supplementation. When discussing spending time outside year-round the health educator may provide information on clothing choices effect vitamin D status. Traditionally, men wear white linen skirts and colorful shawls; however, many have adopted western dress (Centers for Disease Control and Prevention, 2008). As Somalis may cover their skin with clothing more than native Minnesotans, they get less sun exposure and are therefore at greater risk of developing Hv-D.

To promote continuity of care among Somali immigrants in the context of adequate vitamin D status promotion, dietitians and health educators in a variety of health care settings that may care for Somali patients should be competent in this area. To be a licensed provider in Minnesota, dietitians are required to complete 45 continuing education hours every 3 years. These requirements are not subject-specific, however, and adding a cultural competency component specific to immigrant needs should be strongly considered. Minnesota offers continuing education opportunities for dietitians, many of which are in the form of conferences, which represent an ideal setting to provide culturally appropriate education and continuity of care. The National Wellness Institute hosts an annual conference in Minneapolis which could be an ideal catalyst for discussion and development of new programming.

\section{Public Health Implications}


Vitamin D deficiency prevalence is estimated at $40 \%$ in the United States (Mahan et al., 2012). We estimate this prevalence is significantly higher among Somali immigrants in Minnesota leading to increased risk for the development of negative health consequences. This narrative review outlined the cultural characteristics of U.S. Somali immigrants living in Minnesota and detailed specific cultural, environmental, and dietary risk factors for Hv-D. Considering the previous research on vitamin D deficiency and Somali immigration, we offer specific recommendations to public health practitioners, health promotion professionals, health educators, and other local health affiliates. First, healthcare professionals in Minnesota, particularly registered dietitians, should expand their knowledge about Somali culture and risk factors for vitamin D deficiency in this population to help prevent negative health outcomes related to Hv-D. As members of the health communication and advocacy continuum, dietitians can play a key role in understanding dietary deficiencies and engaging in strategies to reduce associated risks. This initial step should improve the effectiveness of health screens for new Somali immigrants including specific measures for vitamin D deficiency.

Next, health communication campaigns should focus on environmental differences between native Somali climates and associated behaviors following immigration. In Minnesota, recent Somali immigrants receive less sunlight when compared to Somalia due to the increase in latitude and weather-related reluctance to spend time outdoors during the winter and the tendency to cover much of their skin with warm clothing. clothes puts them at greater risk for development of vitamin D deficiency than native Minnesotans due to reduced vitamin D synthesis. Risk factors associated with reduced sun exposure need to be understood within the Somali immigrant population using culturally competent information sources. 
Additionally, dietary practices traditional to Somali culture pre-dispose immigrants to Hv-D when combined with reduced sun exposure. A detailed understanding of Somali dietary traditions would assist with clinical screening of new immigrants and lead to tailored health communication and health promotion programs. Vitamin D supplements should be considered within the strong cultural themes among this population. However, the Somali population may be hesitant to alter dietary practices or consider supplementation, a common practice among newly immigrated parents in acculturating populations wanting to protect native behaviors. Additionally, high rates of unemployment, limited financial means, and limited English proficiency and health literacy present as barriers maintaining a healthy diet and supplementation. These factors must be considered when developing new health promotion programming or evaluating existing programs.

The Somali refugee population is one of the most recent to immigrate to the U.S (Njeru et al., 2016), which provides health educators with a challenge and an opportunity. The Somali transition into U.S. communities can include healthy practices associated with vitamin D while maintaining core cultural elements as they begin a new life in Minnesota. Dietitians, health education, and health promotion professionals should assume supportive roles in these processes. Future research should include quantifying prevalence data of Hy-D among the immigrant populations in Minnesota. Enhanced health educator cultural competency combined with knowledge of prevalence data will provide an important foundation to create programs to address Hv-D risk factors among recent Somali immigrants residing in Minnesota.

\section{Limitations}


There are limitations to this narrative review worth mentioning. Methodologies employed in narrative reviews are often less strict, more subjective in nature, do not provide quantitative synthesis, and often offer a holistic interpretation of the literature compared to systematic reviews or meta-analyses. Narrative reviews that do not employ methodologically solid methods, such as the Preferred Reporting Items for Systematic Reviews and Meta-Analyses (PRISMA), may be prone to bias and confounding. Narrative reviews serve to re-introduce and discuss an existing issue rather than present an objective summary of the literature. 


\section{References}

Arcan, C., Larson, N., Bauer, K., Berge, J., Story, M. and Neumark-Sztainer, D. (2014), "Dietary and weight-related behaviors and body mass index among Hispanic, Hmong, Somali, and white adolescents", Journal of the Academy of Nutrition and Dietetics, Vol. 114 No. 3, pp. 375-83.

Benbenek, M. M. and Garwick, A. W. (2012), "Enablers and barriers to dietary practices contributing to bone health among early adolescent Somali girls living in Minnesota", Journal for specialists in pediatric nursing, Vol. 17 No. 3, pp. 205-14.

Binkley, N., Gemar, D., Engelke, J., Gangnon, R., Ramamurthy, R., Krueger, D. and Drezner, M. K. (2011), "Evaluation of ergocalciferol or cholecalciferol dosing, 1,600 IU daily or 50,000 IU monthly in older adults", The Journal of clinical endocrinology and metabolism, Vol. 96 No. 4, pp. 981-8.

Carroll, J., Epstein, R., Fiscella, K., Gipson, T., Volpe, E. and Jean-Pierre, P. (2007), "Caring for Somali women: implications for clinician-patient communication", Patient education and counseling, Vol. 66 No. 3, pp. 337-45.

Centers for Disease Control and Prevention (2008) Promoting Cultural Sensitivity: A Practical Guide for Tuberculosis Programs That Provide Services to Persons from Somalia. Atlanta, GA. Available at: https://www.cdc.gov/tb/publications/guidestoolkits/ethnographicguides/default.htm (Accessed: July 12 2017).

Clarkson Freeman, P. A., Penney, D. S., Bettmann, J. E. and Lecy, N. (2013), "The Intersection of Health Beliefs and Religion Among Somali Refugees: A Qualitative Study", Journal of Religion \& Spirituality in Social Work: Social Thought, Vol. 32 No. 1, pp. 1-13.

Degni, F., Suominen, S., Essen, B., El Ansari, W. and Vehvilainen-Julkunen, K. (2012), "Communication and cultural issues in providing reproductive health care to immigrant women: health care providers' experiences in meeting the needs of [corrected] Somali women living in Finland", Journal of immigrant and minority health, Vol. 14 No. 2, pp. 330-43.

Demeke, T., El-Gawad, G. A., Osmancevic, A., Gillstedt, M. and Landin-Wilhelmsen, K. (2015), "Lower bone mineral density in Somali women living in Sweden compared with AfricanAmericans", Archives of osteoporosis, Vol. 10 No., pp. 208.

Fernell, E., Mohamed, A. A., Martin, H., Bagenholm, G. and Gillberg, C. (2015), "Children born to mothers of Somali origin with severe vitamin D deficiency during pregnancy development at age 4 years", Acta paediatrica, Vol. 104 No. 4, pp. 428-9.

Frei, R., Haile, S. R., Mutsch, M. and Rohrmann, S. (2015), "Relationship of Serum Vitamin D Concentrations and Allostatic Load as a Measure of Cumulative Biological Risk among the US Population: A Cross-Sectional Study", PLoS One, Vol. 10 No. 10, pp. e0139217.

Hadden, R. L., US Army Corps of Engineers (2007) The Geology of Somalia: A Selected Bibliography of Somalian Geology, Geography and Earth Science. Alexandria, VA: Topographic Engineering Center.

Hill, N., Hunt, E. and Hyrkas, K. (2012), "Somali immigrant women's health care experiences and beliefs regarding pregnancy and birth in the United States", Journal of transcultural nursing, Vol. 23 No. 1, pp. 72-81. 
Holick, M. F. (1988), "Skin: site of the synthesis of vitamin D and a target tissue for the active form, 1,25-dihydroxyvitamin D3", Annals of the New York Academy of Sciences, Vol. 548 No., pp. 14-26.

Holick, M. F. (2009), "Vitamin D status: measurement, interpretation, and clinical application", Annals of epidemiology, Vol. 19 No. 2, pp. 73-8.

Ingram, J. (2009), "The health needs of the Somali community in Bristol", Community practitioner, Vol. 82 No. 12, pp. 26-9.

Islam, M. Z., Viljakainen, H. T., Karkkainen, M. U., Saarnio, E., Laitinen, K. and LambergAllardt, C. (2012), "Prevalence of vitamin D deficiency and secondary hyperparathyroidism during winter in pre-menopausal Bangladeshi and Somali immigrant and ethnic Finnish women: associations with forearm bone mineral density", British journal of nutrition, Vol. 107 No. 2, pp. 277-83.

Johnson, C. E., Ali, S. A. and Shipp, M. P. (2009), "Building community-based participatory research partnerships with a Somali refugee community", American journal of preventive medicine, Vol. 37 No. 6 Suppl 1, pp. S230-6.

Kalliokoski, P., Bergqvist, Y. and Löfvander, M. (2013), "Physical performance and 25hydroxyvitamin D: a cross-sectional study of pregnant Swedish and Somali immigrant women and new mothers", BMC Pregnancy and Childbirth, Vol. 13 No., pp. 237-237.

Mahan, L. K., Escott-Stump, S. and Raymond, J. L. (2012) Krause's Food \& the Nutrition Care Process. St. Louis, MO: Elsevier Saunders.

Matyjaszek-Matuszek, B., Lenart-Lipinska, M. and Wozniakowska, E. (2015), "Clinical implications of vitamin D deficiency", Przeglad menopauzalny, Vol. 14 No. 2, pp. 75-81.

Minnesota Department of Health (2014) Minnesota Refugee Health Report - 2013. Available at: http://www.health.state.mn.us/divs/idepc/refugee/stats/13rhrpt.pdf (Accessed: October 9 2016).

Minnesota Department of Health (2017) Primary refugee arrival to minnesota by initial county of resettlement and country of origin. Available at: http://www.health.state.mn.us/divs/idepc/refugee/stats/ (Accessed: October 25 2016).

Minnesota Department of Natural Resources (2017) Normals, Means, And Extremes Minneapolis (KMSP). Minneapolis, MN. Available at: http://files.dnr.state.mn.us/natural resources/climate/summaries and publications/msp n ormals means extremes page3.pdf (Accessed: August 20 2017).

Minnesota State Demographics Center - Department of Administration (2017) Key findings - MN \& EDR Data. Available at: https://mn.gov/admin/demography/data-by-topic/populationdata/our-estimates/ (Accessed: September 23 2017).

Modgil, G., Williams, B., Oakley, G. and Burren, C. P. (2010), "High prevalence of Somali population in children presenting with vitamin D deficiency in the UK", Archives of Disease in Childhood, Vol. 95 No. 7, pp. 568-569.

Morrison, T. B., Wieland, M. L., Cha, S. S., Rahman, A. S. and Chaudhry, R. (2012), "Disparities in preventive health services among Somali immigrants and refugees", Journal of immigrant and minority health, Vol. 14 No. 6, pp. 968-74.

National Cancer Institute, U.S. Department of Health and Human Services and National Institutes of Health (2012) Theory at a Glance: A Guide for Health Promotion Practice. 2nd edn.: CreateSpace Independent Publishing Platform.

Njeru, J. W., Tan, E. M., St Sauver, J., Jacobson, D. J., Agunwamba, A. A., Wilson, P. M., Rutten, L. J., Damodaran, S. and Wieland, M. L. (2016), "High Rates of Diabetes 
Mellitus, Pre-diabetes and Obesity Among Somali Immigrants and Refugees in Minnesota: A Retrospective Chart Review", Journal of immigrant and minority health, Vol. 18 No. 6, pp. 1343-1349.

Osmancevic, A., Demeke, T., Gillstedt, M., Angesjo, E., Sinclair, H., Abd El-Gawad, G. and Landin-Wilhelmsen, K. (2016), "Vitamin D treatment in Somali women living in Sweden

- Two randomized, placebo-controlled studies", Clinical endocrinology, Vol. 85 No. 4, pp. 535-43.

Pavlish, C. L., Noor, S. and Brandt, J. (2010), "Somali immigrant women and the American health care system: discordant beliefs, divergent expectations, and silent worries", Social science \& medicine, Vol. 71 No. 2, pp. 353-61.

Podd, D. (2015), "Hypovitaminosis D: A common deficiency with pervasive consequences", Journal of the American Academy of Physician Assistants, Vol. 28 No. 2, pp. 20-26.

Rhodes, L. E., Webb, A. R., Fraser, H. I., Kift, R., Durkin, M. T., Allan, D., O'Brien, S. J., Vail, A. and Berry, J. L. (2010), "Recommended summer sunlight exposure levels can produce sufficient $(>$ or $=20 \mathrm{ng} \mathrm{ml}(-1)$ ) but not the proposed optimal $(>$ or $=32 \mathrm{ng} \mathrm{ml}(-1)$ ) 25(OH)D levels at UK latitudes", The Journal of investigative dermatology, Vol. 130 No. 5, pp. 1411-8.

Saaf, M., Fernell, E., Kristiansson, F., Barnevik Olsson, M., Gustafsson, S. A. and Bagenholm, G. (2011), "Severe vitamin D deficiency in pregnant women of Somali origin living in Sweden", Acta paediatrica, Vol. 100 No. 4, pp. 612-4.

Statistics Finland (2017) Population - Foreigners in Finland. Helsinki, Finland: national statistical institution in Finland - Finnish Prime Minister's Office. Available at: http://www.stat.fi/tup/suoluk/suoluk_vaesto_en.html\#foreigners (Accessed: March 20 2018).

Steinman, L., Doescher, M., Keppel, G. A., Pak-Gorstein, S., Graham, E., Haq, A., Johnson, D. B. and Spicer, P. (2010), "Understanding infant feeding beliefs, practices and preferred nutrition education and health provider approaches: an exploratory study with Somali mothers in the USA", Maternal \& child nutrition, Vol. 6 No. 1, pp. 67-88.

Sunni, M., Farah, M., Hardie, C., Dhunkal, A. M., Abuzzahab, M. J., Kyllo, J. H., Bellin, M. D., Nathan, B. and Moran, A. (2015), "Understanding Cultural Beliefs in Families of Somali Children with Diabetes in the Twin Cities, Minnesota", Journal of community health, Vol. 40 No. 4, pp. 827-33. 